\title{
Karyotype aberrations and gene mutations characteristics correlated it with UM prognosis
}

\author{
Ying $\mathrm{Mao}^{1}, \mathrm{Bin} \mathrm{Li}^{* 1}$ \\ ${ }^{1}$ Beijing Institute of Ophthalmology. Beijing Tongren Eye Center, Beijing Tongren Hospital, Capital Medical University, Beijing Key Laboratory of Ophthalmology \\ and Visual Sciences, Beijing 100005, China
}

\begin{abstract}
Researchers tried to determined it whether the prognostic of the high incidence karyotype aberrations and gene mutations that had been displayed in uveal melanoma patients. Such as what the prognosis usually was about UM patients with loss of chromosome 3 (monosomy 3 ), polyploidy ( $>2 \mathrm{~N}$ ) or gain of chromosome $8 \mathrm{q}$ that were combined with/without the main gene mutations of BAP1 (BRCA-associated protein 1), EIF1AX (eukaryotic translation factor 1A), GNAQ (Guanine nucleotidebinding protein, q polypeptide), GNA11 (Guanine nucleotide-binding protein, subunit alpha-11) and SF3B1 (splicing factor 3 subunit B1). Through the literatures of recent years, researchers had suggested aberration of karyotypes and mutation of genes were both made in patients with different prognostic results than we had anticipated but allowed us to reassure patients with a good prognosis.
\end{abstract}

\section{Introduction}

Uveal melanoma (UM) was a most prevalence malignancy tumor located in the uveal of the eyes in adults which approximately $50 \%$ of patients had metastatic hepatic disease within 2 to 15 years after diagnosis, as well as happened in the lung, spleen, and bone [1-3]. But most patients were not clearly whether the initial metastatic time because of the potential undetectable micrometastases [1]. Conducted with more deep research on UM Prognostication, it was considered with the multiply significant risk factors that involved with tumor diameter/ thickness/location, TNM stage, age, sex [4] and the new research of the karyotype aberrations and somatic gene mutations characteristics inherent in UM what made patients have different clinical outcomes. Along with the development of cytogenetic analysis, multiplex ligation dependent probe amplification (MLPA), fluorescence-insitu-hybridization (FISH), single nucleotide polymorphism (SNP) array analysis and other advanced analysis method $[5,6]$ that believed karyotype aberrations and gene mutations were high significant and independent prognostic factor than the conventional clinical prognostic factors in UM patients. In this molecular genetic research that made outcomes would be more accuracy and offered sufficient references to evaluate the prognosis of UM patients.

\section{Aberration of karyotypes and gene mutations were confirmed as significant prognostic factors in UM patients}

In the last century, researchers had already attempted to study the molecular genetic aberrations of UM metastases and correlated it with disease progression [7]. Prescher $G$ and his team had studied 180 patients underwent primary enucleation for UM and 30 patients with monosmy 3 In 1996, based on univariate analysis they presented monosomy 3 was the most significant predictor of bad prognosis, followed by tumor diameter and location, suggested age and sex age had no additional predictive value [8]. A year later Lori A. Worley obtained the same conclusion through the analyses of 67 primary UM, considered patients' age, tumor location/size, local tumor invasion through the sclera and epithelioid cell types were not accuracy factors for making individualized clinical decisions, so they presented that detected chromosomal alterations were more precise ways to predict the patients' prognosis than the clinical and pathologic features [9].

Someone considered that the conclusion maybe existed the deviations because of the error of analysis or the technical restriction., so Zelia M. and his companies researched more evidences to confirmed with the similar outcome which involved 299 patients with posterior uveal melanoma in 2016. They verified the results once again the gene expression profile (GEP) class was the strongest and independent prognostic factor in UM patients that compared with clinical features [10].

\section{UM patients' prognosis with aberration of karyotypes UM patients displayed polyploidy}

There was in no difference prognosis with gene mutations of BAP1, SF3B1, EIF1AX, GNAQ, and GNA11 between diploid and polyploidy UM patients. Most of patients with uveal melanoma displayed the karyotypes were near-normal (diploid) with few nonrandom chromosomal changes like monosomy 3 and a gain of chromosome $8 \mathrm{q}$ [7], but some researches showed the karyotype would display polyploidy with a prevalence of $13 \%$ to $18 \%$ based on DNA content $[11,12]$.

What different prognosis between diploid and polyploidy combined with gene mutations in UM patients that questioned by

Correspondence to: Bin Li, Beijing Institute of Ophthalmology, Beijing Tongren Hospital, Capital Medical University, 17 Hougou lane, Chongnei Street, Beijing 100005, China; E-mail: libin43_99@163.com

Key words: metastasis, prognosis, loss of chromosome 3 (monosomy 3), polyploidy (>2N), a gain of chromosome 8, BAP1, SF3B1, EIF1AX, GNAQ, GNA11

Received: February 22, 2017; Accepted: March 07, 2017; Published: March 10, 2017 
Yavuzyigitoglu Serdar and his team ,they focused on these questions and detected $202 \mathrm{UM}$ patients within twenty-three patients had a polyploid UM karyotype (11.4\%). Results showed there was in no difference prognosis with these main gene mutations between diploid and polyploidy UM patients. In addition, compared with diploid UM suggested BAP1 deficiency was still the most significant prognostic predictor of metastasis in patients with polyploidy UM karyotype (a 16-fold increased hazard ratio), polyploidy tumor had larger tumors (15.61 vs. $13.13 \mathrm{~mm}$ ) and it was often associated with loss of chromosome 3 [7].

UM patients displayed in loss of chromosomes 3 (monosomy 3) or gain of chromosome $8 \mathrm{q}$ were both highly correlative with bad prognosis

The karyotypes of UM patients were mainly displayed monosomy 3 and gain of chromosome 8q [7] which both showed bad prognosis [1319]. Researchers had further investigated uveal melanomas prognostic situations with nonrandom alterations affecting chromosomes 1, 3, 6, and 8 and clinical features. In 2005 Emine Kilic Nicole C. Naus and his coworkers assess the disease-free survival $\mathbb{D} \mathrm{DFS} \bigotimes$ in the 120 tumors from UM patients of numerical changes in chromosomes 1, 3, 6 and 8 , in the univariate analysis that showed epithelioid cells ,the diameter of largest tumor ,loss of chromosome 3 and the gain of chromosome 8q were associated with the prognosis that shorter DFS (from diagnosis to presence of metastases or end of study was 45 months range from 6 to 142 months), and each of them was independent prognostic predictor for the DFS and decreased DFS in UM patients [13]. Van den Bosch $\mathrm{T}$ was put forward similar conclusion that compared with Emine Kilic Nicole C. Naus, He studied 220 choroidal and ciliary body melanomas, regarded monosomy 3 (Hazard ratio $[\mathrm{HR}] 2.83, \mathrm{P}=0.002$ ) and gain of chromosome $8 \mathrm{q}(\mathrm{HR} 3.13, \mathrm{P}=0.002)$ as the most highly independent and important prognostic factors [14]. Meanwhile Ewens, K. G had also took more steps to confirmed these opinions and got same outcome [19].

\section{UM patients displayed in loss of chromosomes 3 (monosomy 3 )}

Monosomy 3 UM patents were highly related with the prognosis. As early as 1990 HOesman DE had already suggested this theory [15]. After that in 1996 Prescher G and his coworkers identified 54 UM, concluded loss of chromosome 3 in UM patients was with high risk of metastasis and approximately half of them with poor survival (the 3 -year relapse-free survival rate was 50\%) that compared to the disomy $\mathrm{UM}$, also suggested monosomy $3 \mathrm{UM}$ patients with lower mortality (lower the mortality rate of $50 \%$ after at 10 to 15 years) [8]. Meanwhile from 1998 to 2009 Damatlo B and his coworkers summarize their cases and evidences showed monosomy 3 was displayed in $50-60 \%$ of primary tumors, despite successful treatment of the primary tumor and lack of frontier knowledge that limited their ability to interpret the accuracy survival data, at least it was confirmed that monosomy 3 was correlated with bad prognosis (strongly with metastatic death, data indicating a reduction in the 5-year survival from $100 \%$ to less than $50 \%)[2,16]$.

\section{UM patients displayed the gain of Chromosome 8q}

Chromosome 8q was strongly linked with UM prognosis. Compared with monosomy 3 UM patients' research, none had intensively focused on chromosome 8 . But the aberration of chromosome 8 had been verified that it was associated with poor prognosis in UM patients [17-19]. In 1997, Sisley K and his team studied 42 UM patients that concluded gain of chromosome 8 was associated significantly with the decreased survival as well as the result will be worsen that combined with chromosome 3 [17] from 1994 to 2014 David W. Hammond studied 75 primary UM cases. The ratio of the main chromosomes alterations in patients were chromosome $1 \mathrm{p}-/ \mathrm{q}+(40 \%)$, monosomy 3 (51\%), chromosome $6 \mathrm{p}+(40 \%)$, chromosome $8 \mathrm{q}+(75 \%)$ and chromosome $8 \mathrm{p}-(28 \%)$, after series of accuracy analysis they supposed the strongly prognostic indicator was gain of chromosome $8 \mathrm{q}$ together with monosomy 3 [hazard ratio of 10.1 ( $\mathrm{P}<0.0001$.)], multiple $8 \mathrm{q}+$ was associated with shorter survival, but neither $8 \mathrm{p}$ deletion nor focal changes affecting chromosome 8 were related with prognosis [18] in 2013. Ewens, K. G's team presented an idea were incompletely same with David W. Hammond's opinion, with 320 UM cases to assess the independent contribution of aberration of chromosome 1, 3, 6 and 8 for prognostication of metastasis. They also believed loss of chromosome $8 \mathrm{p}$ was still an independent prognostic factor [19]. Combined with all the research data that indicated chromosome $8 \mathrm{q}$ was strongly linked with UM prognosis.

By the way Justis P. Ehlers and his coworkers reported the gain of chromosome $8 \mathrm{q}$ was significant correlated with the expression gene located at 8q24 named Development and differentiation enhancing factor 1(DDEF1). Suggested the high-grade uveal melanomas with chromosome $8 \mathrm{q}$ may amplify by the DDEF1 overexpression and was strongly relevant with the UM metastasis (thereby blocking cell spreading and promoting cell motility to increased invasion and metastatic potential of high-grade uveal melanoma) [20].

\section{UM patients' prognosis with genetic aberrations}

\section{UM patients with BAP1}

BAP1 mutation in UM patients was associated with rapid and early metastasis and sharply decreased the patient DFS. From 1990 to 2013, Ewens KG with his team studied the prognostic relevance in these UM somatic mutations of BAP1, SF3B1, EIF1AX, GNAQ, and GNA11,116 patients had been detected. Combined with the recent years' assumption, they believed BAP1 mutation (OR 6.3, 95\% CI 2.714.4) was positively associated with the presence of metasitasis [21].

J. William Harbour had also tried to search for the metastaticrelated mutations in highly metastatic UM during that time, $\mathrm{He}$ identified a susceptibility allele 26 of 31 (84\%) metastasizing tumors with BAP1 mutation on chromosome 3p21.1. Combined with other data that strongly implicated BAP1 mutations occured later in UM progression and as a key event in the acquisition of metastatic competence in UM patients [22]. The Similar outcome presented by Ewens KG and his team in 2014 [21]. A deeper understanding of BAP1 mutation mentioned by Serdar Yavuzigitolu in 2016, Patients without BAP1 mutation would be diagnosed at the oldest age (mean, 66.9 years) [23] and BAP1 deficiency was still the most significant prognostic predictor of metastasis in patients with polyploidy UM karyotype [7].

\section{UM patients with EF1AX mutation}

EIF1AX mutation was almost treated as a rare protective factor to prevent metastatic in UM patients. This theory had supported by Ewens KG [21]. More relative evidences presented in Martin M's study, he divided two distinct classes based on gene expression profiles and chromosome 3, EIF1AX mutations in 16 of 66 UM (24\%), 15 of 31 UM with disomy 3 (48\%) which rarely metastasize and 1 of $35 \mathrm{UM}$ with monosomy 3 (3\%) which were associated with bad prognosis [24]. We could also obtain the prognostic value of the EIFAX mutation in UM patients from professor Serdar Yavuzigitolu's research in 2016. 
With 151 patients filtrated, 28 of 133 tumors DNA samples $(21.1 \%)$ and EIF1AX mutations were associated significantly with disomy 3 and disomy 8q, patients harbored EIFIAX mutation would had extend the disease-free survival (DFS, 190.5 months [mutant] vs. 100.2 months [wild-type]), EIF1AX mutation UM were less metastasis and have a longer DFS than the patients with BAP1 and SF3B1 mutation [23]. With the amount of verified evidences that we could inferred it that EIF1AX had protective value in UM patients.

\section{UM patients with GNAQ and GNA11 mutation}

The influences of GNAQ and GNA11 in the UM patients were inconformity, we could have divided into three groups depended on the diferent viewpoints.

In 2008 Onken MD had analyzed the DNA samples from 67 primary UMs and 22 peripheral blood samples to determined that 24 potential oncogenes that may affect the RAF/MEK/ERK pathway, and GNAQ mutation occurred initial/early in about half of UM patients [25]. A year after 2008 Catherine D. Van Raamsdonk and his team confirmed again the GNAQ mutation mechanism, the gene mutation revealed a constitutive activation in UM cells like activated the MAP-kinase pathway, this data showed GNAQ as a novel oncogene can induced neoplastic melanocytes in UM [26]. But Lack of steady information was available to prove GNAQ and GNA11 mutation was correlated with the prognosis. So, Catherine D. Van Raamsdonk with another team took more samples to investigate the relevance of GNAQ and GNA11 mutation in the prognosis of UM patients in 2010. They suggested these were both had upregulated the MAP kinase pathway and the predominant way in the deterioration of UM was Gaq-Ga11 pathway. Combined with the research evidences that showed $83 \%$ GNAQ or GNA11 mutation in UM patients, they believed the two gene mutations were both relevant with the development of $U M$, in addition they also thought GNA11 mutation had more effects on the UM cells [27].

Different opinions had been put forward by Abdel-Rahman $\mathrm{MH}$ and his coworkers in 2012, they represented some different results compared with Catherine D. Van Raamsdonk. 11 patients involved, the data presented UM patients with mutation in GNAQ and GNA11 would associated with better prognosis in disomy or partial chromosome 3 alterations UM patients that can attain average survival of 69 months (range 40-123 months) [28].

Compared with the above conclusions about the prognostic outcome affected by GNAQ and GNA11 mutations, in 2013 A E Koopmans and his team published a research, 92 UM patients was involved in this study that were focused on analysis of GNAQ and GNA11 mutations in chromosome 1,3,6 and 8. A E Koopmans and his team had thought GNAQ and GNA11 mutation did not correlated with patients' prognosis and GNA11 mutation were not more harmful than GNAQ mutation in UM patients [29]. These theories were dramatically different with Catherine D. Van Raamsdonk's results.

\section{UM patients with SF3B1 mutation}

SF3B1 mutation was associated with better prognosis that had intermediate risk and related with late metastasis and lower DFS compared to the UM patients with BAP1 or EIF1AX mutation .

In 2013 Simon J. Furney and his team published a research, 12 frozen primary UM had been involved in this study. They believed SF3BI mutation was associated with improved outcome, (identified SF3B1 mutations in approximately $15 \%$ of cases and they were associated with better prognosis) and were rarely coincident with BAP1 mutation [30], the same conclusion with J. William Harbourwhich [31]. Martin M detected SF3B1 mutations in 10 of $66 \mathrm{UM}(15 \%), 9$ of 31 UM with disomy 3 (29\%) which rarely metastasize and 1 of 35 UM with monosomy 3 (3\%) which were associated with bad prognosis, the data presented SF3B1 mutation was associated with better prognosis in patients displayed disomy 3 [24]. With more evidences and analyses of the prevalence and prognostic value of SF3B1 in UM patients that had been interpreted by Serdar Yavuzigitolu in 2016, this theory was enhanced by Simon J. Furney and J. William Harbourwhich. 151 tumors were involved in this study, they had almost detected SF3B1 mutations in $10 \%$ to $21 \%$ of cases of UM that mentioned UM patients with gene mutation of SF3B1 had increased risk compared with those patients without the mutation of SF3B1 (DFS, 132.8 vs. 174.4 months; $\mathrm{P}=0.008)$, they also believed that with such a mutation in patients would be more prone to demonstrate late metastases (median, 8.2 years; range, 23-145 months) [23]. Furthermore, Martin M presented SF3B1 mutation were more frequently from male patients compared to UM patients without mutation [32]. Consolidate the information that SF3B1 mutation was supposed to have intermediate risk and related with late metastasis and lower DFS compared to the UM patients with BAP1 or EIF1AX mutation [23].

\section{Conclusion}

Karyotype aberrations and gene mutations characteristics were more significant and independent factors that correlated it with disease progression compared with conventional clinical prognostic factors (tumor diameter, location and thickness). Monosomy 3 and the gain of chromosome 8q were both associated with the prognosis that shorter disease free survival (DFS), furthermore a gain of chromosome $8 \mathrm{q}$ significantly will be worsen that combined with chromosome 3. There was no big different prognosis in UM patients displayed diploid and polyploidy that were combined with same BAP1 SF3B1, EIF1AX, GNAQ and GNA11 mutations. In additional polyploidy was often associated with loss of chromosome 3 .

BAP1 mutation UM was associated with rapid and early metastasis and sharply decreased the patient DFS, EIF1AX mutation was almost treat as a rare protective factor to prevent metastatic and have extend a longer DFS, SF3B1 mutation that had intermediate risk and was related with late metastasis and lower DFS. The GNAQ and GNA11's role in the UM patients were not clearly, they divided into three groups based on the different opinions. A group of researchers suggested GNAQ and GNA11 were both as novel oncogene that can induced neoplastic melanocytes in UM and GNA11 mutation had more effects on the UM cells. the second group of professors presented an opposite result that suggested UM patients with mutation in GNAQ and GNA11 would be associated with a better prognosis. The third group of experts presented GNAQ and GNA11 mutation were not correlated with patients' prognosis and GNA11 mutation were not more harmful than GNAQ mutation in UM patients.

I supposed the controversy among in this research was caused by the Lack of steady information, error of analysis or unavoidable technical restrictions. So, we need to accumulated sufficient data, seek more advanced technology and statistical methods to prove and confirm the outcomes of the prognostic factors' effects in the UM patients.

\section{Financial support and sponsorship}

Supported by Beijing Natural Sciences Foundation (7162036) 


\section{References}

1. Bakalian S, Marshall JC, Logan P, Faingold D, Maloney S, et al. (2008) Molecular pathways mediating liver metastasis in patients with uveal melanoma. Clin Cancer Res 14: 951-956. [Crossref]

2. Lorigan JG, Wallace S, Mavligit GM (1991) The prevalence and location of metastases from ocular melanoma: imaging study in 110 patients. AJR Am J Roentgenol 157: 1279-1281. [Crossref]

3. Eskelin S, Pyrhönen S, Hahka-Kemppinen M, Tuomaala S, Kivelä T (2003) A prognostic model and staging for metastatic uveal melanoma. Cancer 97: 465-475. [Crossref]

4. Damato B, Coupland SE (2009) Translating uveal melanoma cytogenetics into clinical care. Arch Ophthalmol 127: 423-429. [Crossref]

5. Luscan A, Just PA, Briand A, Burin des Roziers C, Goussard P, et al. (2015) Uveal melanoma hepatic metastases mutation spectrum analysis using targeted nextgeneration sequencing of 400 cancer genes. Br J Ophthalmol 99: 437-439. [Crossref]

6. Vaarwater J, van den Bosch T, Mensink HW, van Kempen C, Verdijk RM, et al. (2012) Multiplex ligation-dependent probe amplification equals fluorescence in-situ hybridization for the identification of patients at risk for metastatic disease in uveal melanoma. Melanoma Res 22: 30-37. [Crossref]

7. Yavuzyigitoglu S, Mensink HW, Smit KN, Vaarwater J, Verdijk RM, et al. (2016) Metastatic disease in polyploid uveal melanoma patients is associated with BAP1 mutations. Invest Ophthalmol Vis Sci 57: 2232-2239. [Crossref]

8. Prescher G, Bornfeld N, Hirche H, Horsthemke B, Jöckel KH, et al. (1996) Prognostic implications of monosomy 3 in uveal melanoma. Lancet 347: 1222-1225. [Crossref]

9. Worley LA, Onken MD, Person E, Robirds D, Branson J, et al. (2007) Transcriptomic versus chromosomal prognostic markers and clinical outcome in uveal melanoma. Clin Cancer Res 13: 1466-1471. [Crossref]

10. Corrêa ZM, Augsburger JJ (2016) Independent Prognostic Significance of Gene Expression Profile Class and Largest Basal Diameter of Posterior Uveal Melanomas. Am J Ophthalmol 162: 20-27. [Crossref]

11. Toti P, Greco G, Mangiavacchi P, Bruni A, Palmeri ML, et al. (1988) DNA ploidy pattern in choroidal melanoma: correlation with survival. A flow cytometry study on archival material. Br J Ophthalmol 82: 1433-1437. [Crossref]

12. Mooy C, Vissers K, Luyten G, Mulder A, Stijnen T, et al. (1995) DNA flow cytometry in uveal melanoma: the effect of pre-enucleation irradiation. Br J Ophthalmol 79: 174177. [Crossref]

13. Kilic E, Naus NC, van Gils W, Klaver CC, van Til ME, et al. (2005) Concurrent loss of chromosome arm $1 \mathrm{p}$ and chromosome 3 predicts a decreased disease-free survival in uveal melanoma patients. Invest Ophthalmol Vis Sci 46: 2253-2257. [Crossref]

14. van den Bosch T, van Beek JG, Vaarwater J, Verdijk RM, Naus NC, et al. (2012) Higher percentage of FISH-determined monosomy 3 and $8 \mathrm{q}$ amplification in uveal melanoma cells relate to poor patient prognosis. Invest Ophthalmol Vis Sci 53: 26682674. [Crossref]

15. Horsman DE, Sroka H, Rootman J, White VA (1990) Monosomy 3 and isochromosome $8 \mathrm{q}$ in a uveal melanoma. Cancer Genet Cytogenet 45: 249-253. [Crossref]

16. Damato B (2008) Choroidal melanoma endoresection, dandelions and allegory-based medicine. Br J Ophthalmol 92: 1013-1014. [Crossref]
17. Sisley K, Rennie IG, Parsons MA, Jacques R, Hammond DW, et al. (1997) Abnormalities of chromosomes 3 and 8 in posterior uveal melanoma correlate with prognosis. Genes Chromosomes Cancer 19: 22-28. [Crossref]

18. Hammond DW, Al-Shammari NS, Danson S, Jacques R, Rennie IG, et al. (2015) HighResolution Array CGH Analysis Identifies Regional Deletions and Amplifications of Chromosome 8 in Uveal Melanoma. Invest Ophthalmol Vis Sci 56: 3460.

19. Ewens KG, Kanetsky PA, Richards-Yutz J, Al-Dahmash S, De Luca MC, et al. (2013) Genomic profile of 320 uveal melanoma cases: chromosome 8p-loss and metastatic outcome. Invest Ophthalmol Vis Sci 54: 5721-5729. [Crossref]

20. Ehlers JP, Worley L, Onken MD, Harbour JW (2005) DDEF1 is located in an amplified region of chromosome $8 \mathrm{q}$ and is overexpressed in uveal melanoma. Clin Cancer Res 11: 3609-3613. [Crossref]

21. Ewens KG, Kanetsky PA, Richards-Yutz J, Purrazzella J, Shields CL et al. (2014) Chromosome 3 Status Combined With BAP1 and EIF1AX Mutation Profiles Are Associated With Metastasis in Uveal Melanoma. Invest Ophthalmol Vis Sci 55: 51605167. [Crossref]

22. Harbour JW, Onken MD, Roberson ED, Duan S, Cao L, et al. (2010) Frequent mutation of BAP1 in metastasizing uveal melanomas. Science 330: 1410-1413. [Crossref]

23. Yavuzyigitoglu S, Koopmans AE, Verdijk RM, Vaarwater J, Eussen B, et al. (2016) Uveal Melanomas with SF3B1 Mutations: A Distinct Subclass Associated with LateOnset Metastases. Ophthalmology 123: 1118-1128. [Crossref]

24. Martin M, Maßhöfer L, Temming P, Rahmann S, Metz C, et al. (2013) Exome sequencing identifies recurrent somatic mutations in EIF1AX and SF3B1 in uveal melanoma with disomy 3. Nat Genet 45: 933-936. [Crossref]

25. Onken MD, Worley LA, Long MD, Duan S, Council ML, et al. (2008) Oncogenic mutations in GNAQ occur early in uveal melanoma. Invest Ophthalmol Vis Sci 49: 5230-5234. [Crossref]

26. Van Raamsdonk CD, Bezrookove V, Green G, Bauer J, Gaugler L, et al. (2009) Frequent somatic mutations of GNAQ in uveal melanoma and blue naevi. Nature 457: 599-602. [Crossref]

27. Van Raamsdonk CD, Griewank KG, Crosby MB, Garrido MC, Vemula S, et al. (2010) Mutations in GNA11 in uveal melanoma. N Engl J Med 363: 2191-2199. [Crossref]

28. Abdel-Rahman MH, Cebulla CM, Verma V, Christopher BN, Carson WE 3rd, et al (2012) Monosomy 3 status of uveal melanoma metastases is associated with rapidly progressive tumors and short survival. Exp Eye Res 100: 26-31. [Crossref]

29. Koopmans AE, Vaarwater J, Paridaens D, Naus NC, Kilic E, et al. Patient survival in uveal melanoma is not affected by oncogenic mutations in GNAQ and GNA11. $\mathrm{Br} J$ Cancer 109: 493-496. [Crossref]

30. Furney SJ, Pedersen M, Gentien D, Dumont AG, Rapinat A, et al. (2013) SF3B1 mutations are associated with alternative splicing in uveal melanoma. Cancer Discov 3: 1122-1129. [Crossref]

31. Harbour JW1, Roberson ED, Anbunathan H, Onken MD, Worley LA, et al. (2013) Recurrent mutations at codon 625 of the splicing factor SF3B1 in uveal melanoma. Nat Genet 45: 133-135. [Crossref]

32. Martin M, Maßhöfer L, Temming P, Rahmann S, Metz C, et al. (2013) Exome sequencing identifies recurrent somatic mutations in EIF1AX and SF3B1 in uveal melanoma with disomy 3. Nat Genet 45: 933-936. [Crossref]

Copyright: (C2017 Mao Y. This is an open-access article distributed under the terms of the Creative Commons Attribution License, which permits unrestricted use, distribution, and reproduction in any medium, provided the original author and source are credited. 